\title{
PROBABILITAS MINERAL PASIR BESI TITAN YOGYAKARTA BERDASARKAN STUDI PXRF
}

\author{
Mineral Probabilities of Titaniferous Iron Sand \\ from Yogyakarta Based on a pXRF Study
}

\section{IBRAHIM PURAWIARDI, RUSTIADI PURAWIARDI dan FLORENTINUS FIRDIYONO}

Pusat Penelitian Metalurgi dan Material, Lembaga Ilmu Pengetahuan Indonesia (LIPI), Kawasan PUSPIPTEK Gd. 470, Tangerang Selatan 15314, Banten, Indonesia e-mail: ibrahimpurawiardi@gmail.com

\begin{abstract}
ABSTRAK
Pasir besi titan dari Yogyakarta dikarakterisasi menggunakan portable x-ray fluorescence (pXRF) dengan algoritma soil (W-tube, $40 \mathrm{kV}$ ) dan alloy (Rh-tube, $50 \mathrm{kV}$ ). Hasil karakterisasi menggunakan algoritma soil menunjukkan kandungan unsur-unsur Fe (19,71 wt.\%), Ca (5,86 wt.\%), Ti (2,64 wt.\%), K (0,84 wt. \%) dan light elements (70,13 wt.\%), sedangkan hasil karakterisasi menggunakan algoritma alloy menunjukkan kandungan unsur-unsur Fe (52,5 wt. \%), Si (32,7 wt. \%), $\mathrm{Al}(9,1 w t . \%)$ dan Ti (4,74 wt. \%). Analisis mineral berbasis metode algoritma soil menunjukkan adanya dua probabilitas. Probabilitas pertama menunjukkan mineral bijih yang terdeteksi adalah hematit dan ilmenit, sedangkan mineral-mineral non-bijih adalah kuarsa, augit dan biotit. Probabilitas kedua menunjukkan mineral bijih yang terdeteksi hanya ilmenit, sedangkan mineral-mineral nonbijih yang terdeteksi adalah hipersten, kuarsa dan biotit. Analisis mineral berbasis metode algoritma alloy menunjukkan mineral-mineral bijih yang terdeteksi adalah magnetit, hematit dan ilmenit, sedangkan satusatunya mineral non-bijih yang terdeteksi adalah albit.
\end{abstract}

Kata kunci: pasir besi titan, pXRF, mineral bijih, mineral non-bijih, probabilitas.

\begin{abstract}
The titaniferous iron sand from Yogyakarta was characterized by portable $x$-ray fluorescence (pXRF) with two algorithms i.e. soil algorithm (W-tube, $40 \mathrm{kV}$ ) and alloy algorithm (Rh-tube, $50 \mathrm{kV}$ ). Characterization result using soil algorithm shows some elements such as Fe (19.71 wt.\%), Ca (5.86 wt.\%), Ti (2.64 wt.\%), K (0.84 wt.\%) and light elements (70.13 wt.\%). Meanwhile, the result from alloy method shows some elements such as Fe (52.5 wt.\%), Si (32.7 wt.\%), Al (9.1 wt.\%) and Ti (4.74 wt.\%). Based on the soil algorithm method, the mineral analysis result shows two probabilities. The first probability shows two ore minerals i.e. hematite and ilmenite; while quartz, augite and biotite were detected as non-ore minerals. The second probability shows only ilmenite as ore mineral; while hypersthene, quartz and biotite were detected as non-ore minerals. On the other hands, the alloy algorithm method yielded mineral analysis result that shows some ore minerals such as magnetite, hematite and ilmenite; while albite was detected as the only non-ore mineral.
\end{abstract}

Keywords: titaniferous iron sand, pXRF, ore mineral, non-ore mineral, probability.

\section{PENDAHULUAN}

Pasir besi titan (titaniferous iron sand) merupakan salah satu sumber bijih magnetit $\left(\mathrm{Fe}_{3} \mathrm{O}_{4}\right)$ dan ilmenit $\left(\mathrm{FeTiO}_{3}\right)$ (Samanta, Mukherjee dan Dey, 2015; Sarkar dkk., 2018,
2019). Proses metalurgi ekstraktif umumnya dilakukan untuk mengekstrak magnetit dan ilmenit dari pasir besi titan. Magnetit dan ilmenit hasil ekstraksi ini umumnya diproses lebih lanjut dengan proses reduksi hingga menghasilkan besi (Fe) dan titanium dioksida 
$\left(\mathrm{TiO}_{2}\right)$ yang bernilai lebih ekonomis (Samanta, Mukherjee dan Dey, 2015; Sarkar dkk., 2016, 2018). Potensi ini menyebabkan pasir besi titan menjadi salah satu sumber penghasil besi dan titanium yang cukup menjanjikan (Samanta, Mukherjee dan Dey, 2015; Sarkar dkk., 2019). Di samping itu, bila $\mathrm{TiO}_{2}$ hasil reduksi yang dihasilkan merupakan jenis anatas, maka $\mathrm{TiO}_{2}$ ini dapat juga dimanfaatkan sebagai pigmen (Barnard dkk., 2019).

Indonesia sendiri memiliki potensi sumber pasir besi titan, salah satunya di daerah sekitar pantai selatan Yogyakarta. Riset sebelumnya menunjukkan bahwa pasir besi titan dari daerah Yogyakarta ini memiliki potensi mineral bijih magnetit, ilmenit dan hematit (Purawiardi, 1994). Pada riset tersebut, karakterisasi yang digunakan adalah analisis petrogafi bijih, petrografi non-bijih, EPMA dan XRD. Namun, pada riset tersebut karakterisasi menggunakan XRF tidak dilakukan. Oleh sebab itu, pada studi kali ini analisis mineral bijih dan non-bijih pada pasir besi titan dicoba dilakukan menggunakan XRF.

Studi kali ini, digunakan XRF tipe pXRF untuk menganalisis mineral bijih dan non-bijih. Instrumen pXRF sendiri bersifat portable karena mudah dijinjing dengan berat relatif ringan. Alat ini sekarang cukup banyak digunakan pada riset-riset yang memerlukan studi lapangan langsung (in-situ) (Orfanou dan Rehren, 2015; Lynch $d k k$., 2016; Liao $d k k ., 2017$; Magrini $d k k_{.}, 2018$; Tian $d k k ., 2018$; Mauran $d k k_{\text {., }}$ 2019; Rogan $\left.d k k_{.}, 2019\right)$. Mengingat potensi pasir besi titan banyak tersebar di alam Indonesia, penggunaannya akan cukup banyak diminati dalam riset pasir besi titan ke depan. Dengan pXRF, pasir besi titan dapat dideteksi langsung kandungan unsur-unsurnya tanpa harus membawanya ke laboratorium.
Karakterisasi mineral bijih dan non-bijih pada pasir besi titan sendiri sangat diperlukan sebagai acuan dalam menentukan proses metalurgi ekstraktif untuk memisahkan mineral bijih dan non bijih, serta untuk menentukan proses ekstraksi besi dan titanium selanjutnya dari mineral bijihnya.

\section{METODE}

Percontoh yang digunakan adalah pasir besi titan yang diperoleh dari daerah selatan Yogyakarta yang digerus hingga halus terlebih dahulu (-200 mesh) sebelum dikarakterisasi. Percontoh kemudian dikarakterisasi menggunakan portable $x$-ray fluorescence (pXRF) merek Torontech tipe TTEDXpert III. Karakterisasi pXRF ini dilakukan menggunakan dua metode, yaitu metode dengan algoritma soil (W-tube, $40 \mathrm{kV}$ ) dan algoritma alloy (Rh-tube, $50 \mathrm{kV}$ ). Pada metode algoritma soil, rentang unsur yang dapat terdeteksi adalah dari S ( $Z=$ 16) hingga $U(Z=92)$. Sementara pada metode algoritma alloy, terdapat penambahan rentang unsur dari $M g(Z=12)$ hingga $S(Z=16)$.

\section{HASIL DAN PEMBAHASAN}

Hasil karakterisasi pXRF menggunakan kedua metode tersebut di atas dapat dilihat pada Tabel 1. Selanjutnya, hasil karakterisasi ini menjadi dasar dalam analisis mineral. Di dalam analisis mineral ini, unsur-unsur impuritas diabaikan dalam analisis dikarenakan kuantitas kandungannya yang sangat kecil sehingga dapat dipastikan bukan merupakan bagian dari mineral-mineral yang akan dianalisis.

Tabel 1. Hasil karakterisasi pXRF pasir besi titan Yogyakarta

\begin{tabular}{lc}
\hline \multicolumn{2}{c}{ Metode Algoritma Soil } \\
\hline \multicolumn{1}{c}{ Unsur } & $\begin{array}{c}\text { Komposisi } \\
\text { (wt. \%) }\end{array}$ \\
\hline Light Elements $(\mathrm{Si}, \mathrm{Mg}, \mathrm{Al})$ & 70,13 \\
$\mathrm{Fe}$ & 19,71 \\
$\mathrm{Ca}$ & 5,86 \\
$\mathrm{Ti}$ & 2,64 \\
$\mathrm{~K}$ & 0,84 \\
Impuritas & 0,82 \\
\hline
\end{tabular}

\begin{tabular}{lcc}
\hline \multicolumn{2}{c}{ Metode Algoritma Alloy } \\
\hline \multicolumn{1}{c}{ Unsur } & $\begin{array}{c}\text { Komposisi } \\
(w t . \%)\end{array}$ \\
\hline $\mathrm{Fe}$ & 52,50 \\
$\mathrm{Si}$ & 32,70 \\
$\mathrm{Al}$ & 9,10 \\
$\mathrm{Ti}$ & 4,74 \\
Impuritas & 0,96 \\
\end{tabular}




\section{Analisis Mineral dengan Metode Soil (Probabilitas Pertama)}

Untuk menganalisis kandungan mineral hasil karakterisasi metode soil, asumsikan terlebih dahulu unsur-unsur yang bukan light element menjadi senyawa oksida seperti ditunjukkan oleh Tabel 2.

Tabel 2. Komposisi senyawa oksida (metode soil)

\begin{tabular}{ccc}
\hline Oksida & $\begin{array}{c}\text { Komposisi } \\
(\text { wt. } \%)\end{array}$ & $\begin{array}{c}\mathrm{Mr} \\
(\mathrm{g} / \mathrm{mol})\end{array}$ \\
\hline $\mathrm{Fe}_{3} \mathrm{O}_{4}$ & 19,71 & 231,52 \\
$\mathrm{CaO}$ & 5,86 & 56,08 \\
$\mathrm{TiO}_{2}$ & 2,64 & 79,87 \\
$\mathrm{~K}_{2} \mathrm{O}$ & 0,84 & 94,20 \\
\hline
\end{tabular}

Dengan kombinasi oksida, komposisi dan bobot molekul (Mr) seperti pada Tabel 2, akan didapat komposisi secara stoikiometri sebagai berikut:

$10 \mathrm{CaO}+9 \mathrm{Fe}_{3} \mathrm{O}_{4}+3 \mathrm{TiO}_{2}+\mathrm{K}_{2} \mathrm{O}$

Persamaan (1) ini belum memperhitungkan senyawa yang terbentuk oleh light element. Senyawa-senyawa ini adalah senyawa berbasis $\mathrm{Mg}, \mathrm{Al}, \mathrm{Si}, \mathrm{P}$ atau $\mathrm{S}$ dan akan diperhitungkan dalam analisis mineral.

Dalam analisis ini, komposisi senyawa-senyawa berbasis light elements secara stoikiometri yang digunakan adalah sebagai berikut:

$26 \mathrm{SiO}_{2}+8 \mathrm{MgO}+2 \mathrm{Mg}(\mathrm{OH})_{2}+\mathrm{Al}_{2} \mathrm{O}_{3}$.

Persamaan (1) dan (2) selanjutnya digabungkan untuk memprediksi mineral yang terkandung pada pasir besi titan.

Kombinasi antara Persamaan (1) dan (2) selanjutnya dipecah menjadi tiga bagian menjadi Persamaan (3), (4) dan (5) sebagai berikut:

$10 \mathrm{CaO}+2 \mathrm{Fe}_{3} \mathrm{O}_{4}+8 \mathrm{MgO}+20 \mathrm{SiO}_{2} .$.

$3 \mathrm{Fe}_{3} \mathrm{O}_{4}+3 \mathrm{TiO}_{2}$

$\mathrm{K}_{2} \mathrm{O}+4 \mathrm{Fe}_{3} \mathrm{O}_{4}+2 \mathrm{Mg}(\mathrm{OH})_{2}+$

$\mathrm{Al}_{2} \mathrm{O}_{3}+6 \mathrm{SiO}_{2}$
Dari Persamaan (3), (4) dan (5) ini dapat diprediksi mineralnya seperti yang ditunjukkan oleh Persamaan (6), (7) dan (8) berikut ini:

$10 \mathrm{CaO}+2 \mathrm{Fe}_{3} \mathrm{O}_{4}+8 \mathrm{MgO}+20 \mathrm{SiO}_{2}$

$\rightarrow 10 \mathrm{Ca}\left(\mathrm{Mg}_{0.8} \mathrm{Fe}_{0.2}\right) \mathrm{Si}_{2} \mathrm{O}_{6}+2 \mathrm{Fe}_{2} \mathrm{O}_{3}$

$3 \mathrm{Fe}_{3} \mathrm{O}_{4}+3 \mathrm{TiO}_{2} \rightarrow 3 \mathrm{FeTiO}_{3}+3 \mathrm{Fe}_{2} \mathrm{O}_{3}$.. (7)

$\mathrm{K}_{2} \mathrm{O}+4 \mathrm{Fe}_{3} \mathrm{O}_{4}+2 \mathrm{Mg}(\mathrm{OH})_{2}+\mathrm{Al}_{2} \mathrm{O}_{3}+6 \mathrm{SiO}_{2}$

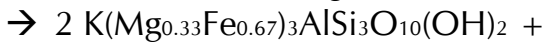
$4 \mathrm{Fe}_{2} \mathrm{O}_{3}$

Persamaan (6), (7) dan (8) ini didasarkan kepada kesetimbangan stoikiometri asumsi reaksi dengan asumsi hasil reaksinya. Hasil analisis mineral gabungan dari asumsi hasil reaksi (6), (7) dan (8) akan diperoleh Persamaan (9) berikut ini:

$10 \mathrm{Ca}\left(\mathrm{Mg}_{0.8} \mathrm{Fe}_{0.2}\right) \mathrm{Si}_{2} \mathrm{O}_{6}+9 \mathrm{Fe}_{2} \mathrm{O}_{3}+3$

$\mathrm{FeTiO}_{3}+2 \mathrm{~K}\left(\mathrm{Mg}_{0.33} \mathrm{Fe}_{0.67}\right)_{3} \mathrm{AlSi}_{3} \mathrm{O}_{10}(\mathrm{OH})_{2} \ldots$. (9)

Perlu diperhatikan bahwa Persamaan (2) yang merupakan gabungan senyawa berbasis light element bila bobot molekulnya diperhitungkan secara keseluruhan hanya akan menghabiskan 21,03 wt. \% senyawa berbasis light element. Oleh sebab itu, dengan total komposisi light elements pada Tabel 1 yang mencapai 70,13 wt. \%, akan tersisa 49,1 wt. \% senyawa berbasis light element yang belum terpakai. Senyawa ini tentunya merupakan senyawa mineral yang memungkinkan memiliki derajat liberasi besar. Kemungkinan terbesar senyawa mineral bebas pada tipe bijih magnetit seperti ini adalah kuarsa - $\mathrm{SiO}_{2}$ (Gurman dan Shcherbak, 2018). Dengan perhitungan bobot molekul (Mr) $\mathrm{SiO}_{2}$ sebesar $60.09 \mathrm{~g} / \mathrm{mol}$, akan diperoleh sisa $\mathrm{SiO}_{2}$ yang belum terpakai secara stoikiometri sebesar 82 mol. Dengan adanya tambahan 82 mol $\mathrm{SiO}_{2}$ ini, Persamaan (9) dapat disempurnakan menjadi Persamaan (10) berikut ini:

$82 \mathrm{SiO}_{2}+10 \mathrm{Ca}\left(\mathrm{Mg}_{0.8} \mathrm{Fe}_{0.2}\right) \mathrm{Si}_{2} \mathrm{O}_{6}+$

$9 \mathrm{Fe}_{2} \mathrm{O}_{3}+3 \mathrm{FeTiO}_{3}+$

$2 \mathrm{~K}\left(\mathrm{Mg}_{0.33} \mathrm{Fe}_{0.67}\right)_{3} \mathrm{AlSi}_{3} \mathrm{O}_{10}(\mathrm{OH})_{2}$

Persamaan (10) inilah yang merupakan komposisi aktual pasir besi titan. Dari hasil ini dapat diperoleh mineral-mineral kuarsa - $\mathrm{SiO}_{2}$, augit - $\mathrm{Ca}\left(\mathrm{Mg}_{0.8} \mathrm{Fe}_{0.2}\right) \mathrm{Si}_{2} \mathrm{O}_{6}$ (Gualtieri, 2000), hematit - $\mathrm{Fe}_{2} \mathrm{O}_{3}$, ilmenit - $\mathrm{FeTiO}_{3}$ dan biotit $\mathrm{K}\left(\mathrm{Mg}_{0.33} \mathrm{Fe}_{0.67}\right)_{3} \mathrm{AlSi}_{3} \mathrm{O}_{10}(\mathrm{OH})_{2}$ (Bohlen, Peacor dan Essene, 1980). Hematit dan ilmenit 
merupakan kategori mineral bijih pada pasir besi titan. Oleh sebab itu dapat dipastikan bahwa kuarsa, augit dan biotit yang merupakan kategori silikat merupakan mineral-mineral non-bijihnya.

\section{Analisis Mineral dengan Metode Soil (Probabilitas Kedua)}

Hasil analisis yang tercantum pada Persamaan (10) bukan satu-satunya probabilitas analisis metode soil. Perlu diingat bahwa probabilitas yang pertama mengasumsikan senyawa oksida berbasis unsur Fe yang digunakan sebagai awal perhitungan adalah $\mathrm{Fe}_{3} \mathrm{O}_{4}$ (Tabel 2).

Pada probabilitas metode soil yang kedua ini, senyawa oksida berbasis $\mathrm{Fe}$ yang digunakan adalah $\mathrm{FeO}$ yang memiliki bobot molekul (Mr) sebesar 71,84 g/mol. Dengan adanya perubahan asumsi menjadi FeO ini, persamaan stoikiometrinya menjadi sebagai berikut:

$27 \mathrm{FeO}+10 \mathrm{CaO}+3 \mathrm{TiO}_{2}+\mathrm{K}_{2} \mathrm{O}$

Dengan mengacu kepada Persamaan (11) ini, prediksi komposisi senyawa berbasis light element-nya secara keseluruhan agar didapatkan probabilitas mineral dan kesetimbangan stoikiometrik adalah sebagai berikut:

$46 \mathrm{SiO}_{2}+10 \mathrm{MgO}+2 \mathrm{Mg}(\mathrm{OH})_{2}+\mathrm{Al}_{2} \mathrm{O}_{3}($

Selanjutnya, gabungan dari Persamaan (11) dan (12) ini akan menghasilkan persamaan stoikiometri seperti berikut:

$46 \mathrm{SiO}_{2}+27 \mathrm{FeO}+10 \mathrm{CaO}+10 \mathrm{MgO}+$

$3 \mathrm{TiO}_{2}+2 \mathrm{Mg}(\mathrm{OH})_{2}+\mathrm{K}_{2} \mathrm{O}+\mathrm{Al}_{2} \mathrm{O}_{3} \ldots . .$. (13)

Lalu, Persamaan (13) ini dapat dipecah menjadi tiga bagian sekaligus memprediksi mineralnya menjadi Persamaan (14), (15) dan (16) seperti berikut ini:

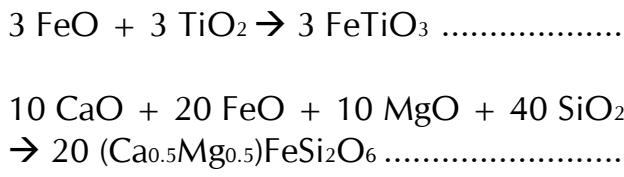

$\mathrm{K}_{2} \mathrm{O}+4 \mathrm{FeO}+2 \mathrm{Mg}(\mathrm{OH})_{2}+\mathrm{Al}_{2} \mathrm{O}_{3}+6 \mathrm{SiO}_{2}$

$\rightarrow 2 \mathrm{~K}\left(\mathrm{Mg}_{0.33} \mathrm{Fe}_{0.67}\right)_{3} \mathrm{AlSi}_{3} \mathrm{O}_{10}(\mathrm{OH})_{2}$

Dari Persamaan (14), (15) dan (16) ini diperoleh mineral-mineral ilmenit - $\mathrm{FeTiO}_{3}$, hipersten -
(Ca0.5 $\left.\mathrm{Mg}_{0.5}\right) \mathrm{FeSi}_{2} \mathrm{O}_{6}$ (Burnham dkk., 1971) dan biotit - $\mathrm{K}\left(\mathrm{Mg}_{0.33} \mathrm{Fe} \mathrm{e}_{0.67}\right)_{3} \mathrm{AlSi} \mathrm{O}_{3} \mathrm{O}_{10}(\mathrm{OH})_{2}$ (Bohlen, Peacor dan Essene, 1980). Ilmenit sendiri merupakan mineral bijih pasir besi titan, sehingga mineral-mineral silikat hipersten dan biotit merupakan kategori mineral-mineral nonbijihnya.

Perlu diperhatikan pula bahwa komposisi senyawa berbasis light elements pada Persamaan (12) hanya akan menghabiskan 33,86 wt. \% komposisi light elements dari total $70,13 w t . \%$ yang tersedia. Oleh sebab itu, terdapat sisa 36,27 wt.\% senyawa berbasis light element yang belum digunakan. Dengan asumsi sisa senyawa tersebut adalah mineral kuarsa - $\mathrm{SiO}_{2}$, maka akan diperoleh tambahan komposisi $60 \mathrm{~mol} \mathrm{SiO}_{2}$ sehingga hasil akhir analisis komposisinya secara stoikiometri adalah sebagai berikut:

$60 \mathrm{SiO}_{2}+20\left(\mathrm{Ca}_{0.5} \mathrm{Mg}_{0.5}\right) \mathrm{FeSi}_{2} \mathrm{O}_{6}+3 \mathrm{FeTiO}_{3}$ $+2 \mathrm{~K}\left(\mathrm{Mg}_{0.33} \mathrm{Fe}_{0.67}\right)_{3} \mathrm{AlSi}_{3} \mathrm{O}_{10}(\mathrm{OH})_{2}$

Dengan mengikuti Persamaan (17) ini, maka di samping hipersten dan biotit, terdapat pula kuarsa yang merupakan salah satu mineral nonbijihnya.

\section{Analisis Mineral dengan Metode Alloy}

Untuk menganalisis mineral yang terkandung pada pasir besi titan berbasis metode alloy, komposisi unsur yang terdeteksi diasumsikan terlebih dahulu menjadi bentuk oksidanya seperti pada Tabel 3.

Dengan kombinasi mineral-mineral oksida beserta komposisi dan bobot molekulnya (Mr) seperti yang ditunjukkan pada Tabel 3, komposisi pasir besi titan ini dapat dituliskan secara stoikiometri sebagai berikut:

$54 \mathrm{SiO}_{2}+23 \mathrm{Fe}_{3} \mathrm{O}_{4}+9 \mathrm{Al}_{2} \mathrm{O}_{3}+6 \mathrm{TiO}_{2} .$. (18)

Dari persamaan (18) ini, digunakan 23 mol $\mathrm{Fe}_{3} \mathrm{O}_{4}$ dan 6 mol $\mathrm{TiO}_{2}$ untuk menganalisis kemungkinan terjadinya mineral bijih. Hasil analisisnya tertuang dalam Persamaan (19) berikut:

$23 \mathrm{Fe}_{3} \mathrm{O}_{4}+6 \mathrm{TiO}_{2} \rightarrow 17 \mathrm{Fe}_{3} \mathrm{O}_{4}+6 \mathrm{FeO} . \mathrm{Fe}_{2} \mathrm{O}_{3}$ $+6 \mathrm{TiO}_{2} \rightarrow 17 \mathrm{Fe}_{3} \mathrm{O}_{4}+6 \mathrm{FeTiO}_{3}+6 \mathrm{Fe}_{2} \mathrm{O}_{3}$ 
Tabel 3. Komposisi senyawa oksida (metode alloy)

\begin{tabular}{lcc}
\hline \multicolumn{1}{c}{ Oksida } & $\begin{array}{c}\text { Komposisi } \\
(\text { wt. \%) }\end{array}$ & $\begin{array}{c}\text { Mr } \\
(\mathrm{g} / \mathrm{mol})\end{array}$ \\
\hline $\mathrm{Fe}_{3} \mathrm{O}_{4}$ & 52,50 & 231,52 \\
$\mathrm{SiO}_{2}$ & 32,70 & 60,09 \\
$\mathrm{Al}_{2} \mathrm{O}_{3}$ & 9,10 & 101,96 \\
$\mathrm{TiO}_{2}$ & 4,74 & 79,87 \\
\hline
\end{tabular}

Hasil analisis Persamaan (19) ini menunjukkan mineral-mineral bijih yang terdeteksi adalah magnetit $\left(\mathrm{Fe}_{3} \mathrm{O}_{4}\right)$, ilmenit $\left(\mathrm{FeTiO}_{3}\right)$ dan hematit $\left(\mathrm{Fe}_{2} \mathrm{O}_{3}\right)$.

Sementara itu, sisa $54 \mathrm{~mol} \mathrm{SiO}_{2}$ dan $9 \mathrm{~mol}$ $\mathrm{Al}_{2} \mathrm{O}_{3}$ digunakan untuk menganalisis mineral non-bijihnya. Analisis mineral non-bijih ini dapat dituliskan dengan Persamaan (20) berikut ini:

$54 \mathrm{SiO}_{2}+9 \mathrm{Al}_{2} \mathrm{O}_{3}+9 \mathrm{X}_{2} \mathrm{O}$

$\rightarrow 18 \mathrm{X}\left(\mathrm{AlSi}_{3} \mathrm{O}_{8}\right)$

Dari persamaan (20) ini terlihat bahwa gabungan antara $54 \mathrm{~mol} \mathrm{SiO}_{2}$ dan 9 mol $\mathrm{Al}_{2} \mathrm{O}_{3}$ hanya memungkinkan membentuk senyawa mineral berbasis aluminosilikat $\left(\mathrm{AlSi}_{3} \mathrm{O}_{8}\right)$. Namun, untuk mencapai kesetimbangan komposisi, diperlukan tambahan senyawa oksida lain dalam bentuk 9 mol $X_{2} \mathrm{O}$. Unsur $\mathrm{X}$ ini tentunya merupakan unsur yang tidak terdeteksi oleh metode alloy. Rentang yang tidak dapat terdeteksi pada metode alloy ini sendiri adalah unsur-unsur dengan nilai Z di bawah 12 (atau di bawah $M g$ ). Kemungkinan unsur yang tidak terdeteksi ini adalah $\mathrm{Na}(Z=$ 11). Na sendiri dapat berikatan dengan $O$ membentuk senyawa oksida $\mathrm{Na}_{2} \mathrm{O}$. Dengan demikian, asumsi yang terkuat senyawa oksida $\mathrm{X}_{2} \mathrm{O}$ ini adalah $\mathrm{Na}_{2} \mathrm{O}$. Dengan tambahan unsur $\mathrm{Na}$ yang menggantikan $\mathrm{X}$ dalam bentuk $\mathrm{Na}_{2} \mathrm{O}$ ini, Persamaan (20) dapat disempurnakan menjadi Persamaan (21) sebagai berikut:

$54 \mathrm{SiO}_{2}+9 \mathrm{Al}_{2} \mathrm{O}_{3}+9 \mathrm{Na}_{2} \mathrm{O}$

$\rightarrow 18 \mathrm{Na}\left(\mathrm{AlSi}_{3} \mathrm{O}_{8}\right)$

Dari Persamaan (21) ini dapat terlihat bahwa probabilitas terkuat mineral non-bijih pada pasir besi titan ini adalah $\mathrm{Na}\left(\mathrm{AlSi}_{3} \mathrm{O}_{8}\right)$ atau lazim disebut albit (Armbruster $d k k$., 1990).

\section{Komparasi Metode Soil dan Metode Alloy}

Dari hasil analisis mineral menggunakan metode soil dan alloy diperoleh beberapa probabilitas mineral bijih dan non-bijih pada percontoh pasir besi titan. Mineral bijih pada pasir besi titan adalah mineral oksida yang mengandung $\mathrm{Fe}$ dan $\mathrm{Ti}$, sedangkan mineral non-bijihnya adalah mineral golongan silikat dan aluminosilikat.

Dengan metode soil akan diperoleh prediksi mineral bijihnya yaitu ilmenit dan hematit. Sementara mineral non-bijih yang dapat diprediksi adalah hipersten, augit, biotit dan kuarsa. Menggunakan metode alloy akan didapatkan prediksi mineral bijih magnetit, ilmenit dan hematit, sedangkan mineral nonbijih yang terprediksi adalah albit.

Kelebihan metode soil adalah dapat memprediksi lebih banyak mineral non-bijih (hipersten, augit, biotit dan kuarsa) namun tidak dapat memprediksi mineral bijih utama yaitu magnetit. Di sisi lain, metode alloy memiliki kelebihan dapat memprediksi mineral bijih utama magnetit, namun hanya mampu memprediksi satu jenis saja mineral non-bijih (albit). Dengan pemaparan ini, kedua metode tersebut harus digunakan secara bersamaan dan dikomparasikan satu sama lain agar memperoleh prediksi mineral bijih dan non-bijih secara maksimal. Dari pemaparan ini pula dapat terlihat bahwa untuk pasir besi titan, metode alloy jauh lebih efektif digunakan untuk memprediksi mineral bijih secara maksimal, sementara metode soil lebih efektif digunakan untuk memprediksi mineral nonbijih secara maksimal.

\section{KESIMPULAN}

Hasil analisis pXRF secara keseluruhan menunjukkan bahwa pasir besi titan Yogyakarta mengandung mineral bijih magnetit, ilmenit dan hematit. Di samping itu, terdapat pula mineral-mineral non-bijih seperti hipersten, augit, kuarsa, biotit dan albit.

Untuk kasus percontoh pasir besi titan, metode algoritma alloy pada pXRF jauh lebih efektif digunakan untuk mendeteksi mineral-mineral bijih dan metode algoritma soil pada pXRF 
lebih efektif digunakan untuk mendeteksi mineral-mineral non-bijih.

\section{UCAPAN TERIMA KASIH}

Ucapan terima kasih disampaikan kepada Laboratorium Pusat Penelitian Fisika - LIPI atas izin untuk menggunakan fasilitas alat karakterisasi pXRF.

\section{DAFTAR PUSTAKA}

Armbruster, T., Bürgi, H. B., Kunz, M., Gnos, E., Brönnimann, S. dan Lienert, C. (1990) "Variation of displacement parameters in Structure refinements of low albite," American Mineralogist, 75, hal. 135-140.

Barnard, K. R., McDonald, R. G., Pownceby, M. I., Sparrow, G. J. dan Zhang, W. (2019) "Processing anatase ores for pigment production," Hydrometallurgy, 185, hal. 226237. doi: 10.1016/j.hydromet.2019.02.006.

Bohlen, S. R., Peacor, D. R. dan Essene, E. J. (1980) "Crystal chemistry of a metamorphic biotite and its significance in water barometry," American Mineralogist, 65, hal. 55-62.

Burnham, C. W., Ohashi, Y., Hafner, S. S. dan Virgo, D. (1971) "Cation distribution and atomic thermal vibrations in an iron-rich orthopyroxene," American Mineralogist, 56, hal. 850-876.

Gualtieri, A. F. (2000) "Accuracy of XRPD QPA using the combined Rietveld-RIR method," Journal of Applied Crystallography, 33(2), hal. 267-278. doi: 10.1107/S002188989901643X.

Gurman, M. A. dan Shcherbak, L. I. (2018) "Process mineralogy and pre-treatment of the poperechny deposit magnetite ore," Journal of Mining Science, 54(3), hal. 497-506. doi: 10.1134/S1062739118033918.

Liao, S., Tao, C., Li, H., Zhang, G., Liang, J. dan Yang, W. (2017) "Use of portable X-ray fluorescence in the analysis of surficial sediments in the exploration of hydrothermal vents on the Southwest Indian Ridge," Acta Oceanologica Sinica, 36(7), hal. 66-76. doi: 10.1007/s13131-017-1085-0.

Lynch, S. C., Locock, A. J., Duke, M. J. M. dan Weber, A. W. (2016) "Evaluating the applicability of portable-XRF for the characterization of Hokkaido Obsidian sources: a comparison with INAA, ICP-MS and EPMA," Journal of Radioanalytical and Nuclear Chemistry, 309(1), hal. 257-265. doi: 10.1007/s10967-016-4766-9.

Magrini, D., Attanasio, D., Bracci, S., Cantisani, E. dan Prochaska, W. (2018) "Innovative application of portable X-ray fluorescence (XRF) to identify Göktepe white marble artifacts," Archaeological and Anthropological Sciences, 10(5), hal. 1141-1152. doi: 10.1007/s12520-016-0444-7.

Mauran, G., Lebon, M., Détroit, F., Caron, B., Nankela, A., Pleurdeau, D. dan Bahain, J.-J. (2019) "First in situ pXRF analyses of rock paintings in Erongo, Namibia: results, current limits, and prospects," Archaeological and Anthropological Sciences, 11(8), hal. 41234145. doi: 10.1007/s12520-019-00787-7.

Orfanou, V. dan Rehren, T. (2015) "A (not so) dangerous method: pXRF vs. EPMA-WDS analyses of copper-based artefacts," Archaeological and Anthropological Sciences, 7(3), hal. 387-397. doi: 10.1007/s12520-0140198-z.

Purawiardi, R. (1994) "Karakteristik bijih dari pasir besi titan Yogyakarta," Berita Teknologi Bahan dan Barang Teknik, 7, hal. 20-25.

Rogan, G., Tighe, M., Grave, P., Kealhofer, L., Yukongdi, P. dan Wilson, S. C. (2019) "Optimization of portable X-ray fluorescence spectrometry for the assessment of soil total copper concentrations: application at an ancient smelting site," Journal of Soils and Sediments, 19(2), hal. 830-839.

doi: 10.1007/s11368-018-2091-3.

Samanta, S., Mukherjee, S. dan Dey, R. (2015) "Upgrading metals via direct reduction from poly-metallic titaniferous magnetite ore," JOM, 67(2), hal. 467-476. doi: 10.1007/s11837014-1203-9.

Sarkar, B. K., Samanta, S., Dey, R. dan Das, G. C. (2016) "A study on reduction kinetics of titaniferous magnetite ore using lean grade coal," International Journal of Mineral Processing, 152, hal. 36-45. doi: 10.1016/j.minpro.2016.05.011.

Sarkar, B. K., Kumar, N., Dey, R. dan Das, G. C. (2018) "Optimization of quenching parameters for the reduction of titaniferous magnetite ore by lean grade coal using the Taguchi method and its isothermal kinetic study," Metallurgical and Materials Transactions B, 49(4), hal. 1822-1833. doi: 10.1007/s11663-018-1283-y. 
Sarkar, B. K., Dastidar, M. G., Dey, R., Das, G. C., Chowdhury, S. dan Mahata, D. K. (2019) "Optimization of reduction parameters of quenched titaniferous magnetite ore by boiler grade coal using box-behnken design," Journal of The Institution of Engineers (India): Series D, 100(2), hal. 275-282. doi: 10.1007/s40033-019-00184-3.
Tian, K., Huang, B., Xing, Z. dan Hu, W. (2018) "In situ investigation of heavy metals at trace concentrations in greenhouse soils via portable X-ray fluorescence spectroscopy," Environmental Science and Pollution Research, 25(11), hal. 11011-11022. doi: 10.1007/s11356-018-1405-8. 
